\title{
Asymmetric Dimethylarginine Reduces Nitric Oxide Donor-Mediated Dilation of Arterioles by Activating the Vascular Renin-Angiotensin System and Reactive Oxygen Species
}

\author{
Zoltan Veresh ${ }^{\mathrm{a}, \mathrm{b}}$ Bela Debreczeni ${ }^{\mathrm{c}}$ Janos Hamar ${ }^{\mathrm{c}}$ Pawel M. Kaminski ${ }^{\mathrm{a}}$ \\ Michael S. Wolin ${ }^{a}$ Akos Koller ${ }^{a, c}$ \\ a Department of Physiology, New York Medical College, Valhalla, N.Y., USA; ${ }^{b}$ First Department of Obstetrics \\ and Gynecology, Semmelweis University, Budapest, and 'Department of Pathophysiology and Gerontology, \\ Faculty of Medicine, University of Pecs, Pecs, Hungary
}

\section{Key Words}

Asymmetric dimethylarginine $\cdot$ Arteriolar dilation $\cdot$ Nitric oxide $\cdot$ Oxidative stress $\cdot$ Reactive oxygen species $\cdot$

Vascular renin-angiotensin system

\begin{abstract}
Introduction: We tested the hypothesis that asymmetric dimethylarginine (ADMA) interferes with other mechanisms in addition to inhibition of nitric oxide synthase (NOS). Thus, in skeletal muscle arterioles, in the presence of ADMA, we investigated the dilator effect of an NO donor and increases in flow and aimed to elucidate the underlying mechanisms, including the role of oxidative stress, which is known to reduce the bioavailability of NO. Methods and Results: In isolated rat gracilis skeletal muscle arterioles $(\sim 160 \mu \mathrm{m}$ at $80 \mathrm{~mm} \mathrm{Hg})$, ADMA (similarly to pyrogallol) reduced dilations to sodium nitroprusside (SNP), which was significantly prevented by the presence of superoxide dismutase (SOD) and catalase (CAT): SNP $10^{-8} \mathrm{M}$; control: $43.2 \pm 3 \%$, ADMA: $4.9 \pm 1 \%$, ADMA + SOD/CAT: $30.2 \pm 9 \%(\mathrm{p}<0.05)$. Also, ADMA reduced basal diameter and flow-induced dilations, which were not restored by L-arginine, but prevented by SOD/CAT and by inhibition of $\mathrm{NAD}(\mathrm{P}) \mathrm{H}$ oxidase (but not xanthine oxidase) and by an angiotensin-converting enzyme inhibitor or an angio-
\end{abstract}

tensin type 1 receptor blocker (ARB). ADMA increased the production of reactive oxygen species detected by lucigenin-enhanced chemiluminescence, which was significantly inhibited by SNP or ARB. Conclusion: We suggest that by activating the vascular renin-angiotensin-NAD(P)H oxidase pathway, ADMA elicits oxidative stress, which interferes with the bioavailability of $\mathrm{NO}$ and consequently reduces NO-mediated dilations.

Copyright $\odot 2012$ S. Karger AG, Basel

\section{Introduction}

It has been well established that L-arginine is a substrate for endothelial nitric oxide (NO) synthase (NOS) and thus plays a crucial role in the production of the dilator molecule NO [1]. Our previous studies and those of others demonstrated that extracellular L-arginine (at a concentration of $10^{-5}$ and $10^{-4} \mathrm{M}$ ) can be rapidly taken up by endothelial cells (ECs) and, as a substrate for NOS, increases NO synthesis [1], which is also reflected by the increase in NO-mediated arteriolar dilations [2-4]. Modifying L-arginine with methylation provided a tool to inhibit NOS and thus to investigate the role of $\mathrm{NO}$ in the mediation of vasomotor function [5]. It was found that ex-

\section{KARGER \\ Fax +4161306 1234 \\ E-Mail karger@karger.ch}

www.karger.com (c) 2012 S. Karger AG, Basel

$1018-1172 / 12 / 0494-0363 \$ 38.00 / 0$

Accessible online at:

www.karger.com/jvr
Dr. Zoltan Veresh

First Department of Obstetrics and Gynecology

Semmelweis University

HU-1089 Budapest (Hungary)

Tel. +36206632434, E-Mail vereshzoltan@gmail.com 
ogenously applied methylated L-arginine, such as $\mathrm{N \omega}$-nitro-L-arginine (L-NNA), $\mathrm{N} \omega$-monomethyl-L-arginine (LNMMA) and N $\omega$-nitro-L-arginine-methyl ester (LNAME; at concentrations of $10^{-4}$ and $10^{-3} \mathrm{M}[6,7]$ ) inhibit NOS, with the consequent reduction in NO-mediated vessel dilations [3].

Interestingly, methylation of L-arginine in proteins occurs also in vivo, and methylated L-arginine is released during proteolysis. Among the endogenously methylated $\mathrm{L}$-arginines, asymmetric dimethylarginine (ADMA) is produced in highest concentrations [8]. Importantly, there is growing evidence that plasma levels of ADMA are markedly elevated in many cardiovascular diseases and recognized as a potential risk factor for cardiovascular events. Elevated plasma ADMA concentrations have been demonstrated in patients with hypertension [9], hyperhomocysteinemia [10], coronary artery disease [11], peripheral arterial occlusive disease [12], stroke [13], pulmonary hypertension [14], end-stage renal disease [15] and preeclampsia [16] all of which could be related to changes in the regulation of microvascular resistance. Thus, it was of interest to further elucidate the mechanisms of action of ADMA in the development of vasomotor dysfunction.

It seemed logical that ADMA - by competing with Larginine - inhibits NOS resulting in reduced production of $\mathrm{NO}$ and thus impaired NO-mediated dilator responses [8]. Recently, several studies found unexpected actions of methylated L-arginines $[17,18]$. For example, it has been found that symmetrical methylated L-arginine does not inhibit NOS [19], whereas there are studies challenging the accepted idea and proposed that ADMA - in addition to inhibiting NO synthesis - may activate other mechanisms, which are then responsible for the development of cellular dysfunction [20-25].

Suda et al. [23], for example, demonstrated that chronic treatment of both wild-type and endothelial NOS (eNOS)-deficient mice with ADMA caused vascular lesions and increased superoxide production, and these changes were prevented by either angiotensin-converting enzyme (ACE) inhibitor (ACEI) or angiotensin type 1 $\left(A T_{1}\right)$ receptor blocker $(A R B)$ treatment. In previous studies, we have found that elevated levels of exogenous ADMA reduced dilations of arterioles elicited by increases in flow known to be mediated in part by $\mathrm{NO}$ [26]. However, because flow increases activate NOS we could not test the presence of an NOS-independent mechanism in the observed vasomotor dysfunction $[18,27]$.

Thus, in the present study, we aimed to further test the hypothesis that ADMA increases the level of reactive oxy- gen species (ROS) in the microvascular wall, which then reduces the bioavailability of $\mathrm{NO}$ and dilations, and hypothesized that if ADMA elicits oxidative stress then it should reduce NO donor-induced dilations, a condition, when NO is not produced by NOS in the arteriolar endothelium. It has been established that one of the main sources of ROS is NAD $(\mathrm{P}) \mathrm{H}$ oxidase [28], which can be activated by angiotensin (Ang) II [29]. Thus, we aimed to investigate the role of these pathways. To test these hypotheses, we performed studies on isolated arterioles from rat skeletal muscle known to respond with dilations in response to the NO donor sodium nitroprusside (SNP) and to increases in intraluminal flow and used scavengers of ROS and inhibitors of oxidative enzymes and the renin-angiotensin system (RAS) to elucidate the underlying mechanisms.

\section{Methods}

\section{Animals}

Experiments were carried out on isolated arterioles of male Wistar rats $(n=50$, weight $\sim 350 \mathrm{~g})$. Animals were housed in an animal care facility, were fed standard rat chow and had free access to tap water. All protocols were approved by the Institutional Animal Care and Use Committee. Rats were anesthetized with an intraperitoneal injection of pentobarbital sodium $(50 \mathrm{mg} / \mathrm{kg}$ body weight), and segments of the gracilis muscle were removed. Animals were then euthanized by an additional injection of pentobarbital sodium (150 mg/kg body weight), followed by a bilateral pneumothorax.

\section{Isolation of Gracilis Skeletal Muscle Arterioles and}

Measurement of Changes in Their Diameter

Using microsurgery instruments and an operating microscope, a segment (1.5-2 mm in length) of the gracilis arteriole was isolated, as described in detail previously [30], transferred to an organ chamber and cannulated with two glass micropipettes. The chamber was filled with calcium-containing physiological salt solution (PSS) composed of (in $\mathrm{mm}$ ) $110 \mathrm{NaCl}, 5.0 \mathrm{KCl}, 2.5 \mathrm{CaCl}_{2}$, $1.0 \mathrm{MgSO}_{4}, 1.0 \mathrm{KH}_{2} \mathrm{PO}_{4}, 5.5$ glucose and $24.0 \mathrm{NaHCO}_{3}$ equilibrated with a gas mixture of $10 \% \mathrm{O}_{2}$ and $5 \% \mathrm{CO}_{2}$, balanced with nitrogen at $\mathrm{pH}$ 7.4. Both perfusate and bath solutions were continuously saturated with this gas mixture to mimic the in vivo level of $\mathrm{pO}_{2}$.

Micropipettes were connected with silicone tubing to an adjustable PSS reservoir. In- and outflow pressures were set at 80 $\mathrm{mm} \mathrm{Hg}$ and measured by a pressure servo control system (Living System Instrumentation). Temperature was set at $37^{\circ} \mathrm{C}$. Perfusate flow was measured with a ball flowmeter (Omega) [26]. Agonists were added to the organ chamber, and at each concentration the peak arteriolar response was registered. All salts and chemicals were obtained from Sigma-Aldrich. Solutions were prepared on the day of the experiment. The internal arteriolar diameter was measured by videomicroscopy with a microangiometer (Texas A \& M University System). Changes in arteriolar diameter were continuously recorded with a chart recorder (Cole Parmer) and in 
digital form with a PowerLab system (ADInstruments) connected to a computer and analyzed with PowerLab and Sigma Plot software. During the 1-hour equilibration period, the vessel was allowed to reach a stable active diameter in the presence of $80 \mathrm{~mm}$ $\mathrm{Hg}$ perfusion pressure. To exclude the potential contribution of prostaglandins, all of the experiments were performed in the presence of indomethacin $\left(2.5 \times 10^{-5} \mathrm{M}\right)$.

\section{Effect of ADMA and Pyrogallol on NO Donor (SNP)-Induced} Dilations

In these series of experiments, responses of the arterioles to increasing concentrations of the NO donor SNP $\left(10^{-8}\right.$ to $\left.10^{-6} \mathrm{M}\right)$ were obtained first under control conditions $[2,4,31]$. Then arterioles were incubated with ADMA for $30 \mathrm{~min}$, and vasomotor responses of arterioles were again determined in the continuous presence of ADMA. In the presence of ADMA, the effects of the free-radical scavengers superoxide dismutase (SOD, $120 \mathrm{U} / \mathrm{ml}$ ) and catalase (CAT, $80 \mathrm{U} / \mathrm{ml}$ ) on vasomotor responses of arterioles were assessed [31]. In other experiments, arterioles were incubated with pyrogallol $\left(10^{-6} \mathrm{M}\right.$, for $\left.10 \mathrm{~min}\right)$, a known generator of superoxide $[31,32]$, and agonist-induced responses were obtained in the presence of pyrogallol with or without SOD/CAT.

\section{ADMA-Induced Changes in Flow-Induced Dilation of}

Arterioles

In these series of experiments, changes in the diameter of arterioles were obtained in response to step increases in intraluminal flow $(10,15$ and $20 \mu \mathrm{l} / \mathrm{min})$ at constant intravascular pressure (80 $\mathrm{mm} \mathrm{Hg}$ ) and in the presence of indomethacin [30]. Each flow rate was maintained for 5-10 min to allow the vessel to reach a steadystate diameter. First, flow-induced changes in the arteriolar diameter were measured in control conditions. Then, arterioles were incubated with ADMA for $30 \mathrm{~min}$. We have used $10^{-4} \mathrm{M}$ ADMA to match to the concentration used in previous studies for other methylated L-arginine, such as L-NAME and L-NNA [4, 6, 7, 31].

After incubation with ADMA, arteriolar responses to step increases in intraluminal flow were obtained in the continuous presence of ADMA in the absence or presence of L-arginine $(5 \times$ $10^{-4} \mathrm{M}$, for $30 \mathrm{~min}$ ) or $120 \mathrm{U} / \mathrm{ml} \mathrm{SOD}$ and $80 \mathrm{U} / \mathrm{ml} \mathrm{CAT} \mathrm{(concen-}$ trations which were shown to effectively scavenge superoxide [33] in the present experimental conditions) to assess the contribution of $\mathrm{NO}$ and the role of ROS in the development of flow-induced responses. In other experiments, in the presence of ADMA, oxypurinol, $\left(10^{-4} \mathrm{M}\right)$ was simultaneously administered and flow-induced responses were obtained in the absence or presence of apocynin $\left(3 \times 10^{-4} \mathrm{M}\right)$. To assess the role of RAS in the presence of ADMA in the arteriolar responses to step increases in intraluminal flow, we used quinapril $\left(10^{-5} \mathrm{M}\right.$, for $\left.30 \mathrm{~min}\right)$ or losartan $\left(10^{-5} \mathrm{M}\right.$, for $\left.30 \mathrm{~min}\right)$ or the NOS inhibitor L-NAME $\left(10^{-4} \mathrm{M}\right.$, for 30 min) similarly.

\section{ADMA-Induced Changes in Basal Arteriolar Diameter}

The basal arteriolar diameter was measured in response to the administration of ADMA. ADMA-induced changes in the basal diameter were also assessed in the presence of SOD/CAT, oxypurinol $\left(10^{-4} \mathrm{M}\right)$, a xanthine oxidase inhibitor, and apocynin $(3 \times$ $\left.10^{-4} \mathrm{M}\right)$, an inhibitor of NAD(P)H oxidases $[34,35]$. Also, to demonstrate the effect of superoxide on basal arteriolar diameter, arterioles were incubated with pyrogallol $\left(10^{-8}\right.$ to $10^{-6} \mathrm{M}$, for 20 $\mathrm{min})$, in the presence or absence of SOD/CAT.

\section{Detection of Superoxide by Lucigenin-Enhanced}

Chemiluminescence

To asses the production of ROS, we used small femoral rat arteries, which provided sufficient amount of tissue and signals for the measurements. Arteries were removed from the rats $(n=8)$, cleared of connective tissue, immersed in PSS or $10^{-4} \mathrm{M}$ ADMA containing PSS in the presence or absence of SNP or the ARB telmisartan, and were oxygenated and incubated for $30 \mathrm{~min}$ at $37^{\circ} \mathrm{C}$. Then arteries were placed in scintillation vials containing HEPES-buffered $\left(10^{-6} \mathrm{M}\right.$; $\mathrm{pH}$ 7.4) PSS solution, and lucigenin $\left(10^{-6} \mathrm{M}\right.$; Calbiochem) chemiluminescence was measured in a liquid scintillation counter (Beckman LS-6000IC), as described previously [26]. Scintillation counts were obtained $20 \mathrm{~min}$ after addition of vessels, and background-corrected values were expressed and the values were normalized to the vessel weight.

\section{Statistical Analysis}

Arteriole constriction in response to ADMA is expressed as a percentage of the baseline diameter at an intraluminal pressure of $80 \mathrm{~mm} \mathrm{Hg}$. Peak dilations of arterioles are expressed as changes in arteriolar diameter as a percentage of the maximal dilation of the vessel, defined as the difference of the passive diameter (at $80 \mathrm{~mm} \mathrm{Hg}$ intraluminal pressure in a $\mathrm{Ca}^{2+}$-free PSS containing $10^{-3} \mathrm{M}$ EGTA and $10^{-4} \mathrm{M}$ SNP) and the initial basal diameter of the arterioles (at zero flow condition, at $80 \mathrm{~mm} \mathrm{Hg}$ ) [26]. Statistical analyses were performed by 2-way ANOVA for repeated measures followed by Tukey's post hoc test or Student's t test, as appropriate. $\mathrm{p}<0.05$ was considered statistically significant. Data are expressed as means \pm SEM.

\section{Results}

\section{Effect of ADMA and Pyrogallol on NO Donor-Induced} Responses of Arterioles

After incubation with ADMA, arteriolar dilations in response to the cumulative doses of the NO donor SNP were significantly decreased compared to those of control vessels incubated with PSS. The reduced dilations induced by SNP in the presence of ADMA were significantly increased in the additional presence of SOD/CAT (fig. 1a). In similar conditions, arteriolar dilations to SNP were also measured in the presence of pyrogallol, which is known to generate ROS $[31,32]$. We have found that pyrogallol - similarly to ADMA - reduced SNP-induced dilations, which were significantly increased in the additional presence of SOD and CAT (fig. 1b).

\section{ADMA-Induced Changes in Flow-Induced Responses of Arterioles}

Increases in intraluminal flow $(10,15$, and $20 \mu \mathrm{l} / \mathrm{min})$ elicited substantial dilations of arterioles, which were significantly reduced in the presence of ADMA (fig. 2a) and were significantly increased by the additional presence of 

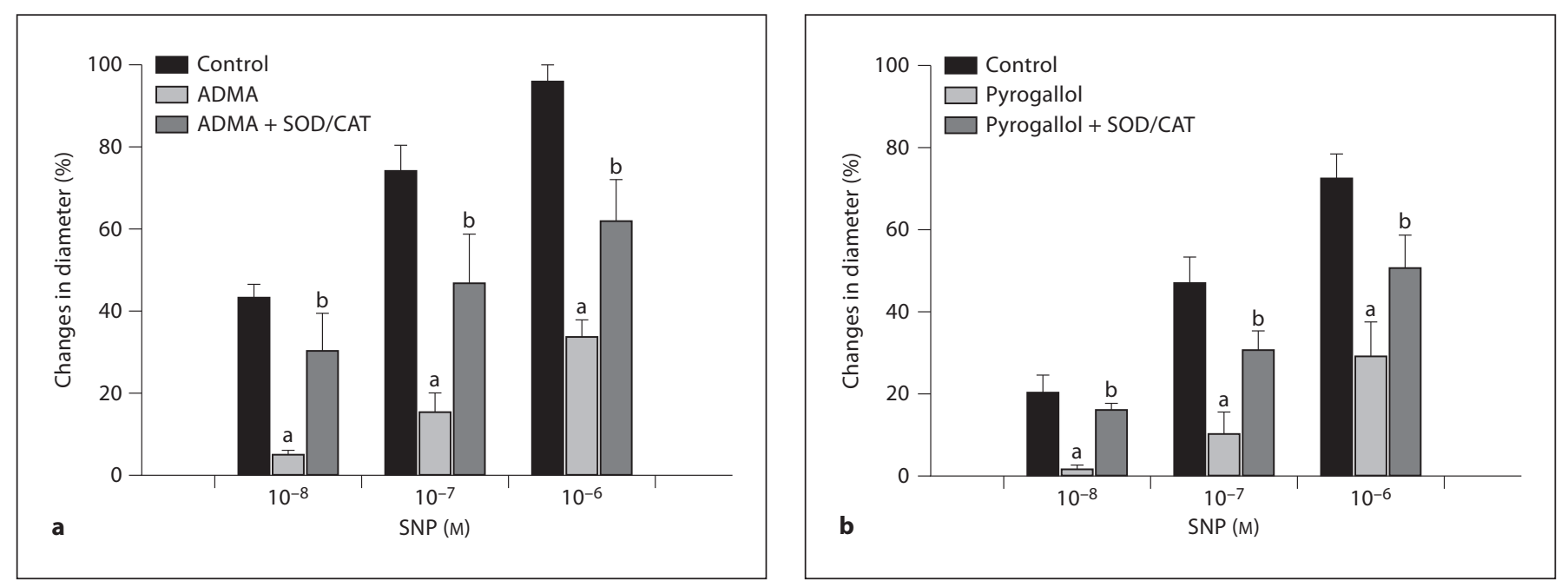

Fig. 1. a Effect of ADMA $\left(10^{-4} \mathrm{M}\right)$ on $\mathrm{NO}$ donor $(\mathrm{SNP})$-induced dilations $(\mathrm{n}=6)$ in the absence or presence of SOD/CAT $(n=6) .{ }^{a} \mathrm{p}<0.05$ vs. control, ${ }^{b} \mathrm{p}<0.05$ vs. ADMA-treated arterioles. b Effect of pyrogallol $\left(10^{-6} \mathrm{M}\right.$, a known superoxide donor) on SNP-induced dilations $(n=6)$ in the absence or presence of ADMA and SOD/ CAT $(n=6)$. Means \pm SEM. ${ }^{a} \mathrm{p}<0.05$ vs. control, ${ }^{b} \mathrm{p}<0.05$ vs. pyrogallol-treated arterioles.

SOD/CAT [18]. In contrast, the additional presence of Larginine did not significantly increase the reduced flowinduced responses in the presence of ADMA (fig. 2a).

Compared to zero flow condition, presence of $20 \mu \mathrm{l} /$ min flow elicited substantial dilation of isolated arterioles, a response, which was inhibited by the presence of ADMA (fig. 2b, c). Presence of oxypurinol did not affect the reduction in flow-induced dilation in the presence of ADMA, whereas in the additional presence of apocynin the dilation induced by flow was not significantly different from the control (fig. 2b). We have also found that flow-induced dilations were preserved at the control level by the presence of the ACEI quinapril or the ARB losartan and the restored dilations were abolished by the presence of LNAME (quinapril: maximum from $33 \pm 3$ and $4 \pm 2 \%$; losartan: maximum from $23 \pm 2$ and $2 \pm 1 \%$; fig. 2 c).

\section{Effect of ADMA and Pyrogallol on Basal Arteriolar Diameter}

An active arteriolar tone developed in response to the presence of an intraluminal pressure of $80 \mathrm{~mm} \mathrm{Hg}$, without the use of any vasoactive agent (active: $153 \pm 4 \mu \mathrm{m}$, passive: $235 \pm 3 \mu \mathrm{m} ; \mathrm{p}<0.05$ ). Summary data show that ADMA elicited a significant decrease in the basal diameter of isolated gracilis muscle arterioles. The presence of SOD/CAT or apocynin inhibited the constrictor effect of ADMA, whereas ADMA-induced constriction was not affected by oxypurinol (fig. 3a). Similarly to ADMA, in- creasing doses of pyrogallol elicited significant decreases in the arteriolar diameter, which was attenuated by the presence of SOD/CAT (fig. 3b).

\section{Assessment of the Role of Oxidative Stress and $A T_{1}$}

Receptors Activity in the Presence of ADMA

A role for ADMA-induced vascular superoxide production was assessed in isolated femoral arteries in control conditions and in the presence of ADMA by the lucigenin-enhanced chemiluminescence method described previously [26]. Summarized data show that ADMA enhanced lucigenin chemiluminescence in arteries (662 \pm 178 and 1,092 \pm 262 chemiluminescence counts/min/100 $\mu \mathrm{g}$ tissue in control and ADMA-treated arteries, respectively), which was significantly inhibited by pre-incubation of the vessels with the NO donor SNP $(583 \pm 136$ chemiluminescence counts/min/100 $\mu \mathrm{g}$ tissue) or the ARB telmisartan (674 \pm 147 chemiluminescence counts/ $\mathrm{min} / 100 \mu \mathrm{g}$ tissue; fig. $4 \mathrm{a}$ ).

\section{Discussion}

The novel findings of the present study are that in isolated rat gracilis muscle arterioles, the presence of ADMA reduced NO donor- and flow-induced dilations. The reduction was prevented by scavengers of ROS, inhibitors of $\mathrm{NAD}(\mathrm{P}) \mathrm{H}$ oxidase, $\mathrm{ACEI}$ or blocking of $\mathrm{AT}_{1}$ receptors, 


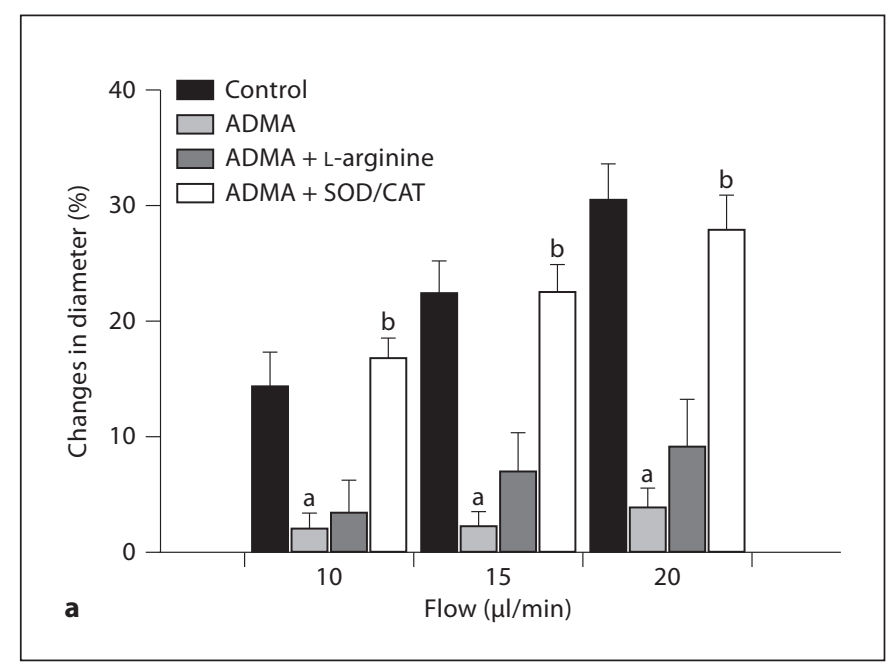

Fig. 2. a Flow-induced changes in the diameter of skeletal muscle arterioles in the presence of increasing levels of intraluminal flow $(10,15$ and $20 \mu \mathrm{l} / \mathrm{min})$ and in the additional presence of L-arginine $\left(5 \times 10^{-4} \mathrm{M}\right)$ or the ROS scavenger SOD/CAT $(\mathrm{n}=8$, respectively). $\mathbf{b}$ Flow-induced changes in the diameter of skeletal muscle arterioles at $20 \mu \mathrm{l} / \mathrm{min}$ flow rate in control conditions, in the presence of ADMA, ADMA plus the xanthine oxidase inhibitor oxypurinol, and ADMA plus oxypurinol plus the $\mathrm{NAD}(\mathrm{P}) \mathrm{H}$ oxidase inhibitor apocynin ( $\mathrm{n}=6,6$ and 4, respectively). c Flow-induced changes in the diameter of skeletal muscle arterioles at $20 \mu \mathrm{l} / \mathrm{min}$ flow rate in control conditions, in the presence of ADMA, in the presence and absence of the ACEI quinapril or ADMA plus the ARB losartan and after administration of the NOS inhibitor LNAME $\left(\mathrm{n}=6,6,6,4\right.$ and 4 , respectively). Means \pm SEM. ${ }^{\mathrm{a}} \mathrm{p}<$ 0.05 vs. control, ${ }^{b} \mathrm{p}<0.05$ vs. ADMA-treated arterioles, ${ }^{\mathrm{c}} \mathrm{p}<0.05$ vs. ADMA plus ACEI or ADMA plus ARB-treated arterioles.

but was not restored by L-arginine. Also, ADMA elicited vascular oxidative stress (indicated by the enhanced lucigenin chemiluminescence), which was inhibited by the $\mathrm{NO}$ donor SNP and blocking of $\mathrm{AT}_{1}$ receptors. Also, pyrogallol mimicked the effects of ADMA. Based on these findings, we hypothesize that by activating the arteriolar RAS-NAD(P)H oxidase pathway ADMA elicits oxidative stress, which then interferes with the bioavailability of $\mathrm{NO}$ and consequently reduces $\mathrm{NO}$-mediated dilations.

\section{Importance of ADMA in Cardiovascular Disease}

Up to now, it seems to be well established that elevated plasma ADMA levels are associated with cardiovascular disease in humans and experimental animals. In several human diseases known to be associated with increased microvascular resistance, such as hypertension [36], dia-
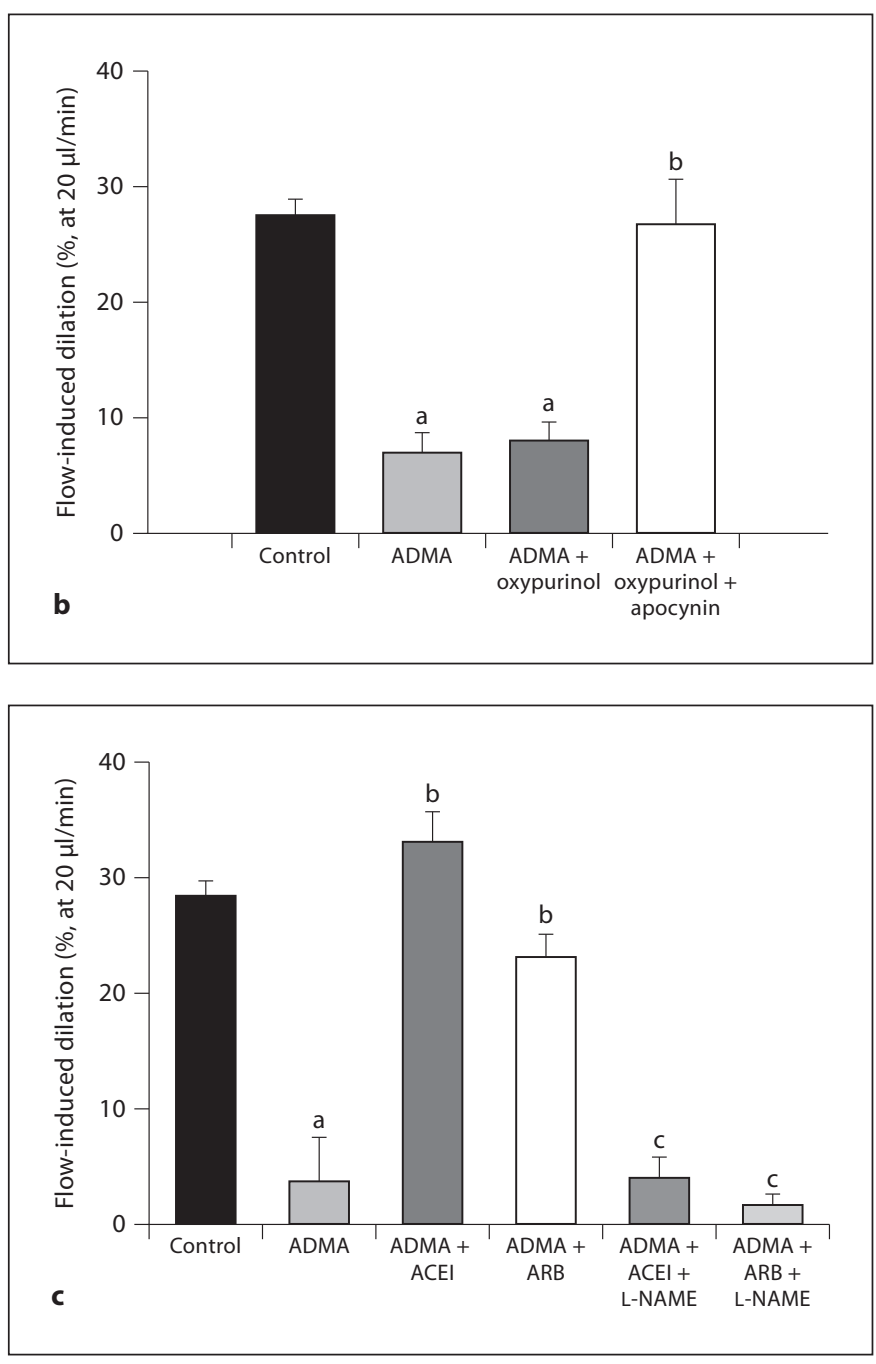

betes [37] and hyperhomocysteinemia $[9,10]$, the serum levels of methylated L-arginines, such as ADMA, are increased. Yet, the precise mechanism of action of ADMA on vasomotor function of microvessels is still debated. Previous studies showed that $10^{-4} \mathrm{M}$ (and $10^{-3} \mathrm{M}$ in some studies) methylated L-arginines, e.g. L-NAME, L-NNA or L-NMMA, inhibit NOS with the consequent reduction in NO-mediated vessel dilations $[3,6,7]$. Thus, the concentration of ADMA used in the present study was similar to concentrations of L-NAME and L-NNA used in many previous studies, allowing us to compare vasomotor findings of ADMA with those of other methylated L-arginines.

Interestingly, precise measurement of the concentration of ADMA still faces technical difficulties and is thus debated [38], but it seems that there is a great difference between the ADMA levels of plasma and intracellular 

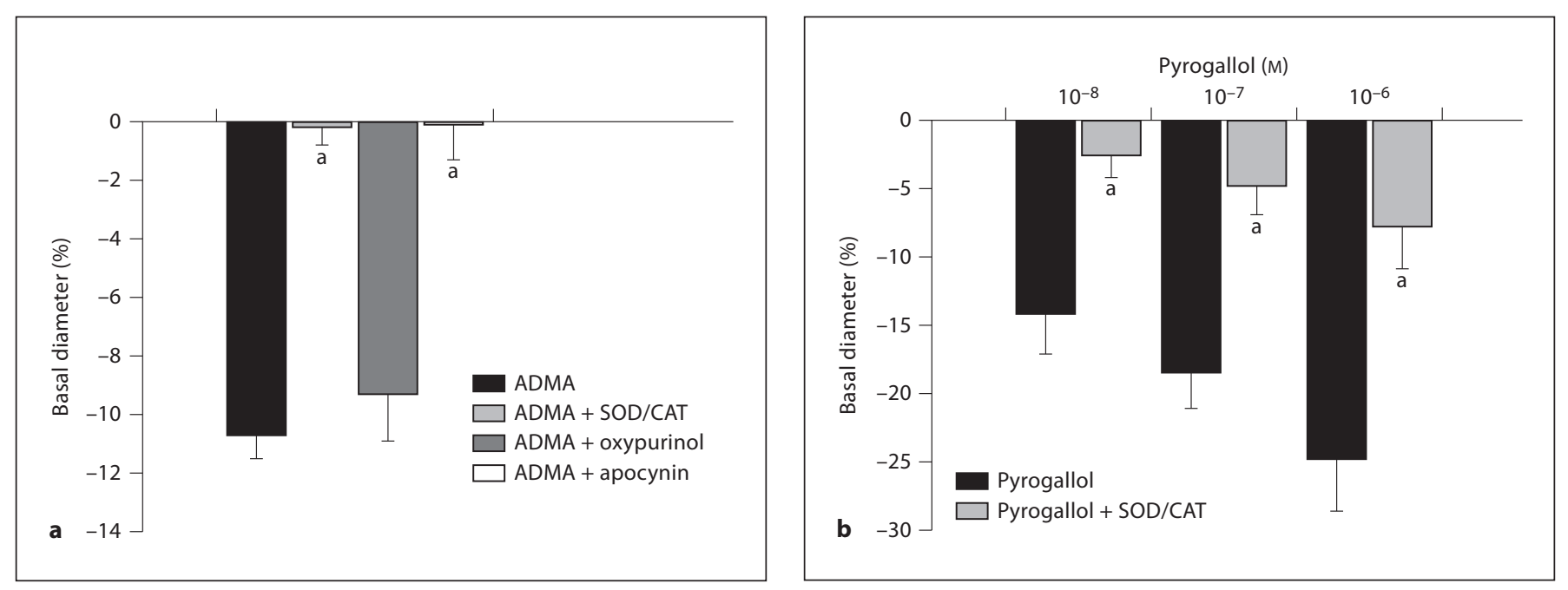

Fig. 3. a Effect of ADMA $\left(10^{-4} \mathrm{M}\right)$ on the basal diameter of skeletal muscle arterioles in control conditions and in the presence of the ROS scavenger SOD/CAT, the xanthine oxidase inhibitor oxypurinol or the NAD $(\mathrm{P}) \mathrm{H}$ oxidase inhibitor apocynin ( $\mathrm{n}=6,6$ and 4 , respectively). Means \pm SEM. ${ }^{\mathrm{a}} \mathrm{p}<0.05$ vs. control. b Effect of pyrogallol (a known superoxide donor) on the basal diameter of skeletal muscle arterioles in control conditions and in the presence of SOD/CAT. Means \pm SEM. ${ }^{a} \mathrm{p}<0.05$ vs. pyrogallol-treated arterioles.

compartments. For example, a recent study reports that the intracellular level of ADMA in red blood cells is 40.6 $\pm 7.2 \mu \mathrm{M}$ [39], whereas other studies suggest that the plasma level of ADMA is around $1 \mu \mathrm{M}$. Methylarginine is transported by the arginine transport system referred to as the $\mathrm{Y}+$ transporter [40] and a 5-fold increase in methylarginine concentration has been shown in ECs when they were exposed to methylarginine added to culture medium $[26,41]$. Also, probably this is the reason why in almost all previous studies $10^{-4} \mathrm{M}$ was the concentration of exogenous L-NNA or L-NAME used to inhibit NOS.

It is also likely that in the intracellular environment ADMA compartmentalizes and reaches even higher concentrations in localized regions and that removal of ADMA might also be a slow process. Taken together, one can assume that the intracellular concentration of ADMA can reach high levels under certain pathophysiological conditions.

\section{Potential Mechanisms of ADMA-Induced \\ Microvascular Dysfunction}

ADMA versus eNOS

As mentioned above, although many studies have been performed to assess the mechanism of action of ADMA, the exact nature of the mechanism(s) remains to be elucidated. A previous study showed that ADMA infusion, which elicited a plasma concentration of $10 \mu \mathrm{M}$, re- duced cardiac output and increased peripheral vascular resistance and thus caused a significant decrease in plasma concentrations of cGMP in healthy humans [42]. However, a decrease in cGMP does not indicate whether the cardiovascular changes observed were due to reduced NO production by NOS or due to oxidative stress-induced reduced bioavailability of NO. Previous studies suggested two mechanisms of action of ADMA: ADMA by compiting with L-arginine inhibits eNOS and thus the release of NO and/or in the presence of ADMA eNOS may become 'uncoupled' due to the absence of appropriate levels of the eNOS substrate L-arginine resulting in the production of superoxide by NOS rather than NO [43]. Interestingly, however, ADMA seems to exert effects that are unrelated to the activity of eNOS $[18,20-25,44]$. For example, ADMA induced coronary microvascular lesions in wild-type and eNOS-knockout mice, which obviously could not be related to NO or uncoupled eNOS [23].

Furthermore, our previous studies showed [45] that LNMMA or L-NNA $\left(10^{-4} \mathrm{M}\right)$ inhibited dilations of rat cremaster muscle arterioles (15-22 $\mu \mathrm{m}$ in diameter) to acetylcholine, which were reversed by subsequent administration of L-arginine. Also, L-NMMA or L-NNA did not reduce dilations to $\mathrm{SNP}$, suggesting that the vasomotor mechanisms of action of L-NMMA, L-NNA and ADMA are different. Supporting this conclusion, others also showed that ADMA increased superoxide production in 


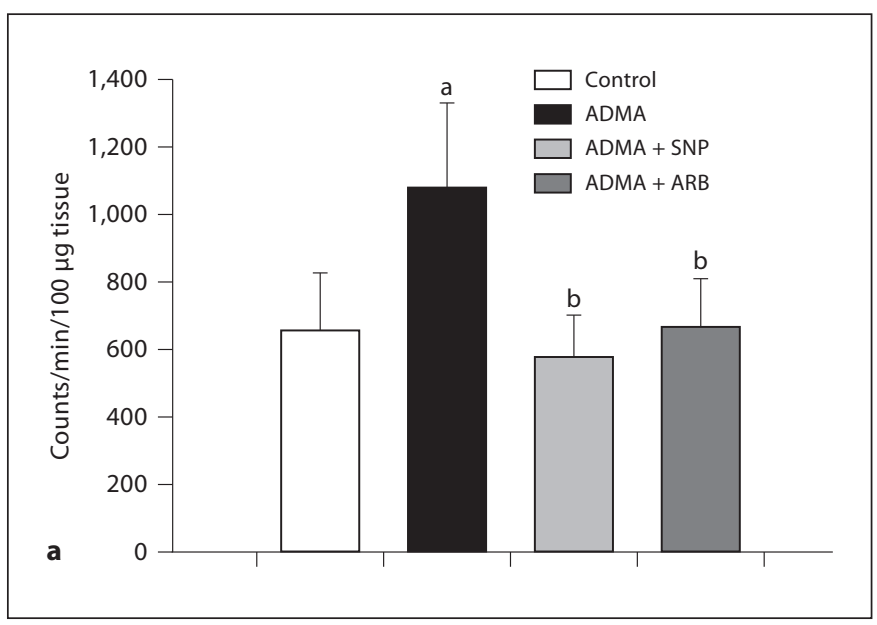

Fig. 4. a Effect of ADMA $\left(10^{-4} \mathrm{M}\right)$ on lucigenin-enhanced chemiluminescence used to detect superoxide anion production in arteries before and after incubation with the NO donor SNP or the ARB telmisartan $(\mathrm{n}=8)$. Means \pm SEM. ${ }^{\mathrm{a}} \mathrm{p}<0.05$ vs. control, ${ }^{\mathrm{b}} \mathrm{p}<0.05$ vs. ADMA-treated arterioles. b Proposed mechanisms by which ADMA elicits oxidative stress and vasomotor dysfunction of arterioles. Elevated levels of ADMA activate the RAS in the arteriolar wall, leading to increased production of Ang II, which then activates $\mathrm{NAD}(\mathrm{P}) \mathrm{H}$ oxidase. The consequent increase in the ROS level interferes with the bioavailability of $\mathrm{NO}$ released from NO donors or from the endothelium in response to increases in flow/shear stress, resulting in diminished NO-mediated dilations, and enhance basal arteriolar tone. Both of these changes favor the development of vasomotor dysfunction.

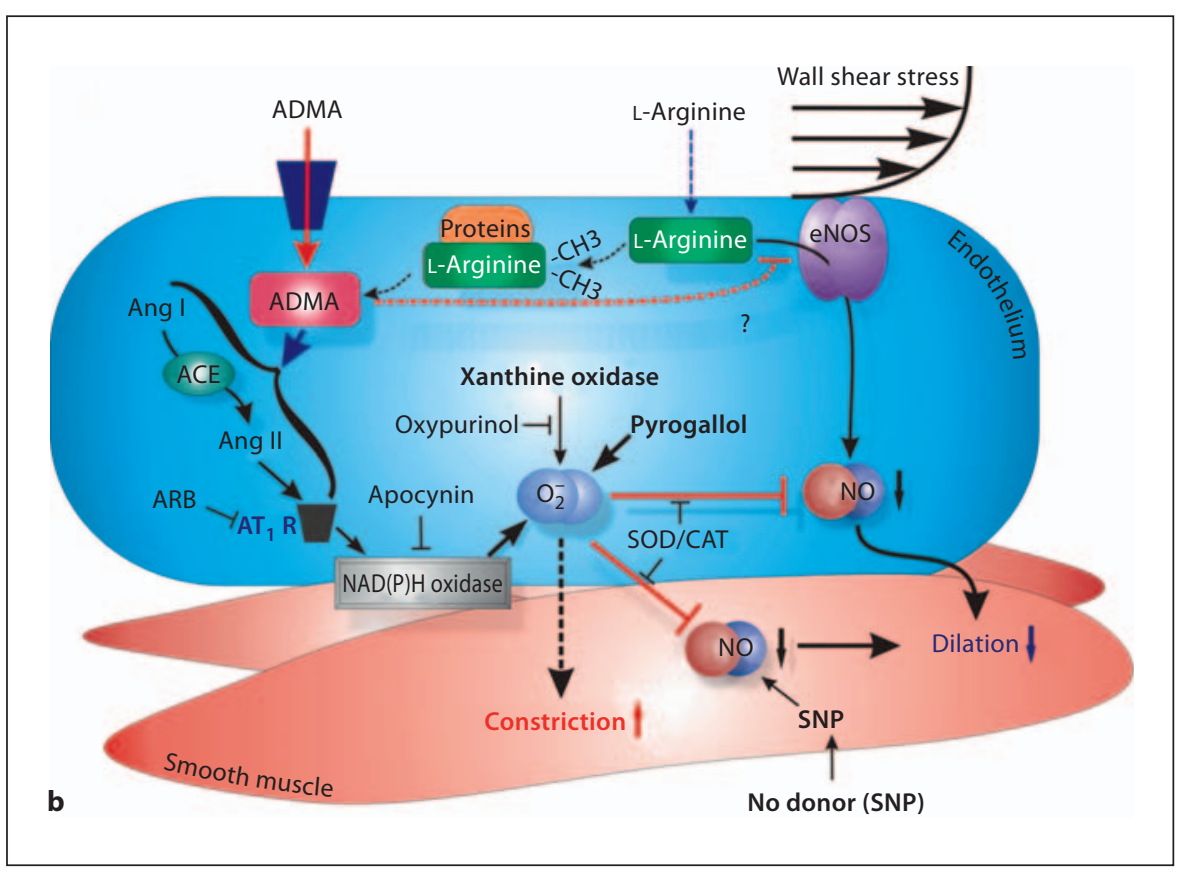

monocytes, and epithelial, endothelial and even cardiac and kidney cells [20, 22, 24, 46, 47]. Furthermore, ADMA impaired glucose utilization and induced ROS and TNF$\alpha$ production in adipocytes and L-arginine, although increased NO release failed to interfere with the effects of ADMA [25]. Another interesting finding also reflects the dichotomy of ADMA and eNOS. Desai et al. [48] reported that erythropoietin, which increased serum ADMA levels, did not compromise NO production, as shown by the increase in NO metabolites in the urine.

These findings suggest that an in vivo mechanism exists by which ADMA increases the vascular level of ROS and that this mechanism is not related to eNOS. If this is the case, then ADMA may reduce an NO donor-induced dilation (which is unrelated to NOS). We have also used indomethacin in these experiments to avoid any potential interference with arachidonic acid metabolites, as shown by our previous studies $[2,4]$.

\section{ADMA versus Superoxide}

SNP is a 'spontaneous' NO donor releasing NO (and $\mathrm{NO}^{+}$) upon dissolution in aqueous solvents; in contrast to nitric acid esters, however, it does not require enzymatic reduction or hydrolysis for this process [49]. We have found that ADMA, similarly to the superoxide producer pyrogallol, significantly reduced the NO donor-induced 
arteriolar dilations, both of which were prevented by the presence of SOD/CAT (fig. 1). Together these findings suggest that increased ROS levels in the presence of ADMA or pyrogallol interfered with the bioavailability of NO released from SNP and thus reduced the dilations. The findings that the presence of apocynin (but not oxypurinol) restored NO-mediated flow-induced dilations in the presence of ADMA (fig. $2 \mathrm{~b}$ ) suggest that ADMA activates $\mathrm{NAD}(\mathrm{P}) \mathrm{H}$ oxidase, which is the primary source of superoxide. This conclusion is further supported by findings that in isolated arteries presence of ADMA increased ethidium bromide fluorescence, an indicator of vascular oxidative stress, which was reduced by apocynin [18]. The primary cellular effect of apocynin is to inhibit the release of superoxide anion by inhibiting NADPH oxidase activity via blocking the migration of $\mathrm{p} 47$ phox to the plasma or microsomal membranes [50].

\section{ADMA versus Uncoupled eNOS}

The findings of the present experiments that L-arginine did not restore flow-induced dilation of arterioles in the presence of ADMA (fig. 2a) argue against the potential role of ROS produced by the uncoupled eNOS. In previous studies, we have found that in the presence of $\mathrm{L}$ NMMA, L-arginine restored NO-mediated dilations to acetylcholine [2], suggesting that differently methylated L-arginines have different mechanism of actions.

\section{Role of $A T_{1}$ Receptor Activation of NAD $(P) H$ Oxidase by $A D M A$}

ADMA elicited significant constriction of arterioles (fig. 3), which were prevented by prior incubation of arterioles with SOD/CAT, apocynin, but not by oxypurinol, suggesting that the constrictions were due to increased levels of superoxide produced by $\mathrm{NAD}(\mathrm{P}) \mathrm{H}$ oxidase rather than xanthine oxidase $[34,36,51]$. In addition, in the presence of ADMA, the ACEI quinapril or the ARB losartan prevented the reduction in the flow-induced dilations of arterioles (fig. 2c). Also, inhibition of NOS with LNAME abolished the 'quinapril- and losartan-restored' flow-induced dilation in the presence of ADMA (fig. 2c). Thus, we propose that RAS and $\mathrm{AT}_{1}$ receptors are primarily involved in the ADMA-Ang II pathway producing ROS, which interferes with the NO released and thus dilations. Thus, it seems that it is the reduced bioavailability of NO, rather than the direct effect of ROS, which interferes with the vasomotor function of arterioles.

Furthermore, presence of ADMA enhanced lucigenin chemiluminescence (fig. 4a), which was reduced by prior incubation of the vessels with the NO donor or blocking
$\mathrm{AT}_{1}$ receptors. These findings support the hypothesis that the RAS in the arteriolar wall is involved in the ADMA-induced oxidative stress and extend our previous findings that ADMA increased oxidative stress indicated by dihydroethidium fluorescence of the arteriolar wall [18], which was significantly reduced toward control levels in the presence of $\mathrm{NAD}(\mathrm{P}) \mathrm{H}$ oxidase inhibitor or blocking $\mathrm{AT}_{1}$ receptors. Similar findings were reported recently by Chen et al. [24], namely that ADMA in human umbilical vein ECs increased ROS formation and reduced NO formation, both of which could be restored by the ARB losartan. Another group [44] has found that in bovine retinal capillary ECs ADMA increased intracellular ROS generation, which was markedly inhibited by the ARB telmisartan, the ACEI benazepril, the reduced form of the $\mathrm{NAD}(\mathrm{P}) \mathrm{H}$ oxidase inhibitor diphenyliodonium, or the antioxidant and free-radical scavenger $\mathrm{N}$-acetyl-L-cysteine [44].

It has been established that Ang II activates NAD $(\mathrm{P}) \mathrm{H}$ oxidase leading to superoxide production $[29,36,51]$; thus, on the basis of the findings of the present study, we propose a potential interaction between ADMA and the RAS in the wall of resistance arterioles [47, 52]. Specifically, by activating microvascular RAS, ADMA may elicit increased production of Ang II, which by activating $\mathrm{NAD}(\mathrm{P}) \mathrm{H}$ oxidase results in an increased production of ROS, which interfere with the biological availability of $\mathrm{NO}$ released from NO donors or in response to flow increases (fig. 4b). If this pathophysiological mechanism is in operation, it may provide an additional mechanism by which inhibitors interfering with vascular RAS exert their beneficial effects on the cardiovascular system.

\section{Proposed Mechanism of Action of ADMA and}

Pathophysiological Consequences of ADMA

We designed the present experiments to investigate the short-term vasomotor effects of ADMA, thus changes observed were unlikely to be due to the up- or downregulation of various genes or altered protein synthesis in the vascular wall. Nevertheless, previous studies showed that chronic treatment with ADMA (4 weeks) upregulated ACE gene expression, activated the local RAS and increased superoxide production, which was abolished by the ACEI temocapril or the ARB olmesartan [23]. During these acute experiments - in control conditions - we did not observe oxidative stress that is likely to be the first sign of pro-inflammation. Also, in many previous studies (ours and others), inflammatory reactions in these conditions were absent (e.g. increased levels of NADPH oxidase, TNF $\alpha$ or NF- $\kappa$ B). However, recently ADMA was 
found to induce rapid phosphorylation of $\mathrm{p} 38 \mathrm{MAPK}$ and markedly stimulated NF-kB activity in human umbilical vein ECs [53]. Thus, one of the potential links between ADMA and RAS [47] could be an ADMA-induced enhancement in p38 MAP kinase activity, because in human coronary artery ECs ACE protein expression has also been shown to be regulated, in part, by the p38 MAP kinase pathway [54]. Therefore, one can suppose that ADMA activates p38 MAP kinase and upregulates ACE expression in ECs, which subsequently hydrolyzes Ang I to Ang II [47]. Endogenous Ang II activates NADPH oxidase and subsequently generates ROS in vascular smooth muscle cells [55].

Because of all the above-mentioned results, it is clear that the vasomotor mechanism of ADMA actions is still not yet clarified, but apparently ADMA exerts a non-NOSdependent action, and to refer to ADMA only as an endog- enous inhibitor of NOS is an oversimplified view. Thus, it is important to further explore the mechanisms by which ADMA exerts its effects on the various tissue functions.

In conclusion, on the basis of the findings of the present and previous studies, we suggest the existence of a novel mechanism: by activating the RAS-NAD $(\mathrm{P}) \mathrm{H}$ oxidase pathway in the microvascular wall ADMA elicits oxidative stress, which interferes with the bioavailability of $\mathrm{NO}$ and, consequently, elicits vasomotor dysfunction (fig. 4b).

\section{Acknowledgments}

The study was supported by the Hungarian National Scientific Research Fund (OTKA) K71591, T67984, the Hungarian Society of Hypertension-2010/2011, the American Heart Association Founders Aff. 0855910D and TAMOP-4.2.1/b-10/2/KONV2010-0012.

\section{References}

1 Schmidt HH, Nau H, Wittfoht W, Gerlach J, Prescher KE, Klein MM, Niroomand F, Bohme E: Arginine is a physiological precursor of endothelium-derived nitric oxide. Eur J Pharmacol 1988;154:213-216.

-2 Sun D, Messina EJ, Koller A, Wolin MS, Kaley G: Endothelium-dependent dilation to Larginine in isolated rat skeletal muscle arterioles. Am J Physiol 1992;262:H1211-H1216.

- 3 Rees DD, Palmer RM, Schulz R, Hodson HF, Moncada S: Characterization of three inhibitors of endothelial nitric oxide synthase in vitro and in vivo. Br J Pharmacol 1990;101: 746-752.

4 Koller A, Sun D, Messina EJ, Kaley G: L-arginine analogues blunt prostaglandin-related dilation of arterioles. Am J Physiol 1993; 264:H1194-H1199.

5 Boucher JL, Moali C, Tenu JP: Nitric oxide biosynthesis, nitric oxide synthase inhibitors and arginase competition for L-arginine utilization. Cell Mol Life Sci 1999;55:10151028.

6 Kenny D, Coughlan MG, Kampine JP, Montgomery RR, Bosnjak ZJ, Warltier DC: Cultured endothelial cells restore vasodilator responses to coronary arteries with impaired endothelial function and alter the response to a nitric oxide donor. Pharmacology 1994; 49:249-256.

7 Qiu HY, Henrion D, Levy BI: Alterations in flow-dependent vasomotor tone in spontaneously hypertensive rats. Hypertension 1994;24:474-479.

$\checkmark 8$ Vallance P, Leone A, Calver A, Collier J, Moncada S: Accumulation of an endogenous inhibitor of nitric oxide synthesis in chronic renal failure. Lancet 1992;339:572-575.
Valkonen VP, Paiva H, Salonen JT, Lakka TA, Lehtimaki T, Laakso J, Laaksonen R: Risk of acute coronary events and serum concentration of asymmetrical dimethylarginine. Lancet 2001;358:2127-2128.

10 Hedner T, Himmelmann A, Hansson L: Homocysteine and ADMA - emerging risk factors for cardiovascular disease? Blood Press 2002;11:197-200.

11 Zeller M, Korandji C, Guilland JC, Sicard P, Vergely C, Lorgis L, Beer JC, Duvillard L, Lagrost AC, Moreau D, Gambert P, Cottin Y, Rochette L: Impact of asymmetric dimethylarginine on mortality after acute myocardial infarction. Arterioscler Thromb Vasc Biol 2008;28:954-960.

12 Mittermayer F, Krzyzanowska K, Exner M, Mlekusch W, Amighi J, Sabeti S, Minar E, Muller M, Wolzt M, Schillinger M: Asymmetric dimethylarginine predicts major adverse cardiovascular events in patients with advanced peripheral artery disease. Arterioscler Thromb Vasc Biol 2006;26:2536-2540.

13 Leong T, Zylberstein D, Graham I, Lissner L, Ward D, Fogarty J, Bengtsson C, Bjorkelund C, Thelle D: Asymmetric dimethylarginine independently predicts fatal and nonfatal myocardial infarction and stroke in women: 24-year follow-up of the population study of women in Gothenburg. Arterioscler Thromb Vasc Biol 2008;28:961-967.

14 Gorenflo M, Zheng C, Werle E, Fiehn W, Ulmer HE: Plasma levels of asymmetrical dimethyl-L-arginine in patients with congenital heart disease and pulmonary hypertension. J Cardiovasc Pharmacol 2001;37: 489-492.
5 Fleck C, Schweitzer F, Karge E, Busch M, Stein G: Serum concentrations of asymmetric (ADMA) and symmetric (SDMA) dimethylarginine in patients with chronic kidney diseases. Clin Chim Acta 2003;336:1-12.

16 Turan F, Ilhan N, Kaman D, Ates K, Kafkasli A: Glu298Asp polymorphism of the endothelial nitric oxide synthase gene and plasma concentrations of asymmetric dimethylarginine in Turkish pre-eclamptic women without fetal growth retardation. J Obstet Gynaecol Res 2010;36:495-501.

17 Al-Zobaidy MJ, Craig J, Martin W: Differential sensitivity of basal and acetylcholine-induced activity of nitric oxide to blockade by asymmetric dimethylarginine in the rat aorta. Br J Pharmacol 2010;160:1476-1483.

18 Veresh Z, Racz A, Lotz G, Koller A: ADMA impairs nitric oxide-mediated arteriolar function due to increased superoxide production by angiotensin II-NAD (P)H oxidase pathway. Hypertension 2008;52:960-966.

19 MacAllister RJ, Fickling SA, Whitley GS, Vallance P: Metabolism of methylarginines by human vasculature; implications for the regulation of nitric oxide synthesis. Br J Pharmacol 1994;112:43-48.

20 Chen MF, Li YJ, Yang TL, Lou B, Xie XM: Losartan inhibits monocytic adhesion induced by ADMA via downregulation of chemokine receptors in monocytes. Eur J Clin Pharmacol 2009;65:457-464.

21 Sydow K, Schwedhelm E, Arakawa N, BodeBoger SM, Tsikas D, Hornig B, Frolich JC, Boger RH: ADMA and oxidative stress are responsible for endothelial dysfunction in hyperhomocyst(e)inemia: effects of L-arginine and B vitamins. Cardiovasc Res 2003; $57: 244-252$. 
-22 Bode-Boger SM, Scalera F, Martens-Lobenhoffer J: Asymmetric dimethylarginine (ADMA) accelerates cell senescence. Vasc Med 2005;10(suppl 1):S65-S71.

-23 Suda O, Tsutsui M, Morishita T, Tasaki H, Ueno S, Nakata S, Tsujimoto T, Toyohira Y, Hayashida Y, Sasaguri Y, Ueta Y, Nakashima Y, Yanagihara N: Asymmetric dimethylarginine produces vascular lesions in endothelial nitric oxide synthase-deficient mice: involvement of renin-angiotensin system and oxidative stress. Arterioscler Thromb Vasc Biol 2004;24:1682-1688.

-24 Chen MF, Xie XM, Yang TL, Wang YJ, Zhang $\mathrm{XH}$, Luo BL, Li YJ: Role of asymmetric dimethylarginine in inflammatory reactions by angiotensin II. J Vasc Res 2007;44:391402.

-25 Yang ZC, Wang KS, Wu Y, Zou XQ, Xiang YY, Chen XP, Li YJ: Asymmetric dimethylarginine impairs glucose utilization via ROS/TLR4 pathway in adipocytes: an effect prevented by vitamin E. Cell Physiol Biochem 2009;24:115-124.

-26 Toth J, Racz A, Kaminski PM, Wolin MS, Bagi Z, Koller A: Asymmetrical dimethylarginine inhibits shear stress-induced nitric oxide release and dilation and elicits superoxide-mediated increase in arteriolar tone. Hypertension 2007;49:563-568.

27 Berry C, Hamilton CA, Brosnan MJ, Magill FG, Berg GA, McMurray JJ, Dominiczak AF: Investigation into the sources of superoxide in human blood vessels: angiotensin II increases superoxide production in human internal mammary arteries. Circulation 2000; 101:2206-2212.

28 Mohazzab KM, Kaminski PM, Wolin MS: $\mathrm{NADH}$ oxidoreductase is a major source of superoxide anion in bovine coronary artery endothelium. Am J Physiol 1994;266: H2568H2572.

29 Griendling KK, Minieri CA, Ollerenshaw JD, Alexander RW: Angiotensin II stimulates NADH and NADPH oxidase activity in cultured vascular smooth muscle cells. Circ Res 1994;74:1141-1148.

\$30 Koller A, Sun D, Huang A, Kaley G: Corelease of nitric oxide and prostaglandins mediates flow-dependent dilation of rat gracilis muscle arterioles. Am J Physiol 1994; 267:H326-H332.

31 Bagi Z, Koller A: Lack of nitric oxide mediation of flow-dependent arteriolar dilation in type I diabetes is restored by sepiapterin. J Vasc Res 2003;40:47-57.

32 Ignarro LJ, Byrns RE, Buga GM, Wood KS, Chaudhuri G: Pharmacological evidence that endothelium-derived relaxing factor is nitric oxide: use of pyrogallol and superoxide dismutase to study endothelium-dependent and nitric oxide-elicited vascular smooth muscle relaxation. J Pharmacol Exp Ther 1988;244:181-189.
33 Huang A, Sun D, Kaley G, Koller A: Superoxide released to high intra-arteriolar pressure reduces nitric oxide-mediated shear stress- and agonist-induced dilations. Circ Res 1998;83:960-965.

34 Beswick RA, Dorrance AM, Leite R, Webb RC: NADH/NADPH oxidase and enhanced superoxide production in the mineralocorticoid hypertensive rat. Hypertension 2001;38: 1107-1111.

35 Williams HC, Griendling KK: NADPH oxidase inhibitors: new antihypertensive agents? J Cardiovasc Pharmacol 2007;50:916.

36 Mollnau H, Wendt M, Szocs K, Lassegue B, Schulz E, Oelze M, Li H, Bodenschatz M, August M, Kleschyov AL, Tsilimingas N, Walter U, Forstermann U, Meinertz T, Griendling $\mathrm{K}$, Munzel T: Effects of angiotensin II infusion on the expression and function of $\mathrm{NAD}(\mathrm{P}) \mathrm{H}$ oxidase and components of nitric oxide/cGMP signaling. Circ Res 2002; 90:E58-E65.

- 37 Hink U, Li H, Mollnau H, Oelze M, Matheis E, Hartmann M, Skatchkov M, Thaiss F, Stahl RA, Warnholtz A, Meinertz T, Griendling K, Harrison DG, Forstermann U, Munzel T: Mechanisms underlying endothelial dysfunction in diabetes mellitus. Circ Res 2001;88:E14-E22.

8 Boger RH, Bode-Boger SM, Szuba A, Tsao PS, Chan JR, Tangphao O, Blaschke TF, Cooke JP: Asymmetric dimethylarginine (ADMA): a novel risk factor for endothelial dysfunction: its role in hypercholesterol emia. Circulation 1998;98:1842-1847.

-39 Billecke SS, Kitzmiller LA, Northrup JJ, Whitesall SE, Kimoto M, Hinz AV, D’Alecy LG: Contribution of whole blood to the control of plasma asymmetrical dimethylarginine. Am J Physiol Heart Circ Physiol 2006; 291:H1788-H1796.

40 Bogle RG, MacAllister RJ, Whitley GS, Vallance P: Induction of NG-monomethyl-Larginine uptake: a mechanism for differential inhibition of NO synthases? Am J Physiol 1995;269:C750-C756.

41 Pullamsetti S, Kiss L, Ghofrani HA, Voswinckel R, Haredza P, Klepetko W, Aigner C, Fink L, Muyal JP, Weissmann N, Grimminger F, Seeger W, Schermuly RT: Increased levels and reduced catabolism of asymmetric and symmetric dimethylarginines in pulmonary hypertension. FASEB J 2005;19:1175-1177.

-42 Kielstein JT, Impraim B, Simmel S, Bode-Boger SM, Tsikas D, Frolich JC, Hoeper MM, Haller H, Fliser D: Cardiovascular effects of systemic nitric oxide synthase inhibition with asymmetrical dimethylarginine in humans. Circulation 2004;109:172-177.

43 Vasquez-Vivar J, Kalyanaraman B, Martasek P, Hogg N, Masters BS, Karoui H, Tordo P, Pritchard KA Jr: Superoxide generation by endothelial nitric oxide synthase: the influence of cofactors. Proc Natl Acad Sci USA 1998;95:9220-9225.
44 Chen YH, Xu X, Sheng MJ, Zheng Z, Gu Q: Effects of asymmetric dimethylarginine on bovine retinal capillary endothelial cell proliferation, reactive oxygen species production, permeability, intercellular adhesion molecule-1, and occludin expression. Mol Vis $2011 ; 17: 332-340$

-45 Blum A, Hathaway L, Mincemoyer R, Schenke WH, Kirby M, Csako G, Waclawiw MA, Panza JA, Cannon RO 3rd: Oral L-arginine in patients with coronary artery disease on medical management. Circulation 2000;101: 2160-2164

46 Wells SM, Holian A: Asymmetric dimethylarginine induces oxidative and nitrosative stress in murine lung epithelial cells. Am J Respir Cell Mol Biol 2007;36:520-528.

47 Hasegawa K, Wakino S, Tatematsu S, Yoshioka K, Homma K, Sugano N, Kimoto M, Hayashi K, Itoh H: Role of asymmetric dimethylarginine in vascular injury in transgenic mice overexpressing dimethylarginie dimethylaminohydrolase 2. Circ Res 2007; 101:e2-e10

48 Desai A, Zhao Y, Warren JS: Human recombinant erythropoietin augments serum asymmetric dimethylarginine concentrations but does not compromise nitric oxide generation in mice. Nephrol Dial Transplant 2008;23:1513-1520.

49 Schroder H: No nitric oxide for HO-1 from sodium nitroprusside. Mol Pharmacol 2006; 69:1507-1509.

-50 Ciarcia R, Damiano S, Panico C, Scanni R Fiorito F, Florio S, Welch JW: Apocynin activity in spontaneously hypertensive rats (SHR): preliminary studies in vivo. Vet Res Commun 2010;34(suppl 1):S83-S86.

- 51 Rajagopalan S, Kurz S, Munzel T, Tarpey M, Freeman BA, Griendling KK, Harrison DG: Angiotensin II-mediated hypertension in the rat increases vascular superoxide production via membrane NADH/NADPH oxidase activation. Contribution to alterations of vasomotor tone. J Clin Invest 1996;97: 1916-1923.

52 Jiang JL, Zhu HQ, Chen Z, Xu HY, Li YJ: Angiotensin-converting enzyme inhibitors prevent LDL-induced endothelial dysfunction by reduction of asymmetric dimethylarginine level. Int J Cardiol 2005;101:153-155.

53 Zhang Q, Chen N, Qiu W, Xu X, Wang D, Tsao PS, Jin H: Asymmetric dimethylarginine impairs fibrinolytic activity in human umbilical vein endothelial cells via p38 MAPK and NF- $\mathrm{B}$ pathways. Thromb Res 2011;128:42-46.

54 Saijonmaa O, Nyman T, Fyhrquist F: Downregulation of angiotensin-converting enzyme by tumor necrosis factor- $\alpha$ and interleukin-1 $\beta$ in cultured human endothelial cells. J Vasc Res 2001;38:370-378.

-55 Seshiah PN, Weber DS, Rocic P, Valppu L, Taniyama Y, Griendling KK: Angiotensin II stimulation of $\mathrm{NAD}(\mathrm{P}) \mathrm{H}$ oxidase activity: upstream mediators. Circ Res 2002;91:406413. 